\title{
In-vitro Evaluation of Anti-Bacterial, Anti-biofilm and Cytotoxic Activity of Naturally Inspired Juglans regia, Tamarix aphylla L., and Acacia modesta with Medicinal Potentialities
}

\author{
Muhammad Khalid ${ }^{1}(\mathbb{D})$ Muhammad Bilal2* (D), Hira Munir ${ }^{3}$, Syed Zakir Hussain \\ Shah $^{4}$ (D) Mohsin Khurshid ${ }^{5}$ (D) Mohamed El-Shazly,7 (D) and Hafiz M.N. Iqbal ${ }^{8}$ (D) \\ ${ }^{1}$ School of Agriculture and Biology, Shanghai Jiao Tong University, Shanghai, 200240, China. ${ }^{2}$ School of Life \\ Science and Food Engineering, Huaiyin Institute of Technology, Huaian 223003, China. ${ }^{3}$ Department of \\ Biochemistry and Biotechnology, University of Gujrat, Pakistan. ${ }^{4}$ Department of Zoology, University of Gujrat, \\ Pakistan. ${ }^{5}$ Department of Microbiology, Government College University Faisalabad, Faisalabad, Pakistan. \\ ${ }^{6}$ Department of Pharmacognosy, Faculty of Pharmacy, Ain-Shams University, Cairo, Egypt. ${ }^{7}$ Department of \\ Pharmaceutical Biology, Faculty of Pharmacy and Biotechnology, German University in Cairo, Cairo, Egypt. \\ ${ }^{8}$ Tecnologico de Monterrey, School of Engineering and Sciences, Campus Monterrey, Ave. Eugenio Garza Sada \\ 2501, Monterrey, N.L., CP 64849, Mexico.
}

\begin{abstract}
The usefulness of medicinal plants has evoked increasing research interests to combat antimicrobial resistance. The current work reports on the in vitro bioactive activities, i.e., antibacterial, anti-biofilm and cytotoxicity evaluation of three medicinal plants. Extracts from different plant parts (leaves, stems, and root barks) were obtained using different solvents, such as methanol, ethanol, and water. The methanolic extracts of bark of Juglans regia and Tamarix aphylla L., whereas the stem of Acacia modesta (Wall.) exhibited the highest antibacterial activity. The maximum zone of inhibition, i.e., $21.8 \pm 0.76 \mathrm{~mm}$ was observed against $\boldsymbol{H}$. influenza for a methanolic extract of $J$. regia. Similarly, the maximum inhibition zones of ethanolic extract of $T$. aphylla $L$. against $A$. baumannii and methanolic extract of $A$. modesta against $S$. aureus were recorded. Notably, a higher anti-biofilm potential of the methanolic extract of $J$. regia was recorded against six pathogenic strains. Finally, the cytotoxicity of plants extracts was evaluated by testing the hemolytic activity against human erythrocytes, that displayed the negligible percent lysis of RBCs. In conclusion, the results of this study provided information related to the possible use of some medicinal plants in the treatment of microbial related ailments.
\end{abstract}

Keywords: Medicinal plants, methanolic extract, bacterial pathogens, antibacterial, anti-biofilm, cytotoxicity

*Correspondence: bilaluaf@hotmail.com

(Received: May 08, 2020; accepted: June 03, 2020)

Citation: Khalid M, Bilal M, Munir H, et al. In-vitro Evaluation of Anti-bacterial, Anti-biofilm and Cytotoxic Activity of Naturally Inspired Juglans regia, Tamarix aphylla L., and Acacia modesta with Medicinal Potentialities. J Pure Appl Microbiol. 2020;14(2):1133-1142. doi: 10.22207/JPAM.14.2.08

(C) The Author(s) 2020. Open Access. This article is distributed under the terms of the Creative Commons Attribution 4.0 International License which permits unrestricted use, sharing, distribution, and reproduction in any medium, provided you give appropriate credit to the original author(s) and the source, provide a link to the Creative Commons license, and indicate if changes were made. 


\section{INTRODUCTION}

The emergence and spread of multidrugresistant (MDR) pathogens are one of the most serious threats to successful treatment of microbial diseases ${ }^{1}$. According to the World Health Organization (WHO), infectious diseases are the 3rd most significant cause of mortality worldwide. Strains such as- $\beta$ lactamase-producing Escherichia coli (BL-EC) and Klebsiella pneumoniae (BL-KP), carbapenem-resistant Enterobacteriaceae, Pseudomonas aeruginosa, hospital-acquired methicillin resistant Staphylococcus aureus (MRSA), and vancomycin resistant Enterococcus (VRE) have been identified as utmost notorious pathogens, thus effective therapies are urgently required for these pathogenic microbes ${ }^{1,2}$. The healing choices for these pathogens are enormously limited and Clinicians are imposed to use expensive drugs associated with noteworthy side consequence to the patients' health ${ }^{1}$. Hence, it is indispensable to find out some substitutions that can possibly be efficient in the treatment of these infections. Practicality, the health beneficial aspects of medicinal components from plants have evoked increasing interest for antimicrobial therapy since they have been evaluated for their probable usages as substitute medications for the treatment of numerous infectious diseases ${ }^{3}$. The WHO estimated that nearly eighty percent of the world's population depend on conventional medication for their central healthcare necessities. The beneficial value of plants lies in bioactive compounds including alkaloids, tannins and phenolic etc. ${ }^{4}$.

Bacteria predominantly grow as either free-living planktonic cells or surface attached biofilms; a highly populated assemblage of bacterial cells surrounded in self-produced polymeric substances including bacterial consortia ${ }^{4}$. This microenvironment of bacteria (biofilm) is one of the foremost pathogenic approaches by infection-causing microbes. Since, it makes them extremely resistant to currently available antibiotics and biocides, as well as immune responses ${ }^{4}$. Biofilm development is facilitated by mechanical, biochemical and genetic factors in bacteria strains ${ }^{5}$. Other than bacterial cells, the major constituent of biofilm is an extracellular polymeric matrix (EPM), composed of polysaccharides, proteins, lipids, polychronic acids and nucleic acids ${ }^{5-7}$. All properties of biofilms, viz. attachment, antibiotic resistance, and phagocytosis may be ascribed to $\mathrm{EPM}^{8}$.

Walnut (Juglans regia L.) is the furthermost prevalent tree nut in the world. It belongs to juglandaceae and has the scientific name Juglans regia. J. regia is a medicinal plant that has been extensively used in traditional medicine for a wide array of ailments ${ }^{8-11}$. Tamarix aphylla (L.) Karst., is another important medicinal plant and belong to the Tamaricaceae family. Acacia belongs to the family Fabaceae or Leguminosa $e^{3,4}$ and displayed noticeable antimicrobial activity against numerous pathogenic microbes ${ }^{5,6}$.

\section{MATERIALS AND METHODS}

\section{Plant material and extract preparation}

Different parts (leaf, stem, and bark) of the plants were locally collected and washed thoroughly (3-4 times) with tap water (to eliminate dirt from the surface). The washed plant materials were dried at room temperature $\left(25^{\circ} \mathrm{C}\right)$ on filter papers. The dried plant materials were ground to fine powder and preserved in polyethylene bags for further use. Two hundred grams of dried powder of each plant was subjected to a maceration process three times with various solvents, i.e., methanol, ethanol, and water at $25^{\circ} \mathrm{C}$. The solvents were removed by subjecting to the rotary evaporator at $45^{\circ} \mathrm{C}$ followed by lyophilization to obtain pure extracts. The extracts were then stored in a refrigerator at $4^{\circ} \mathrm{C}$ for further analysis.

Microbial cultures and inoculum development

Six clinically proven pathogenic microbes, i.e., (1) Staphylococcus aureus (S. aureus), (2) Pseudomonas aeruginosa (P. aeruginosa), (3) Klebsiella pneumoniae (K. pneumoniae), (4) Acenetobacter baumannii (A. baumannii), (5) Marginella morganii (M. morganii) and (6) Haemophilus influenza $(H$. influenza) were used to test the bioactivities of the plant extracts. As collected microbial strains were incubated for $18 \mathrm{~h}$ on a rotary shaker at $37^{\circ} \mathrm{C}$. The 18 -h grown cultures were then diluted appropriately to yield a culture density of approximately $1.5 \times 10^{8} \mathrm{CFU} / \mathrm{mL}$.

\section{Antimicrobial and antibiofilm assay}

The antimicrobial activity of the plant extracts was evaluated using agar well diffusion method $^{12}$. Twenty microliters of plant extracts 
Khalid et al. | J Pure Appl Microbiol | 14(2):1133-1142 | June 2020 | https://doi.org/10.22207/JPAM.14.2.08

Table 1. Antibacterial activity of Juglans regia extracts against bacterial pathogens

\begin{tabular}{|c|c|c|c|c|c|c|c|c|c|}
\hline \multirow{3}{*}{$\begin{array}{l}\text { Leaf } \\
\text { Microorganisms }\end{array}$} & \multirow{3}{*}{ Origin } & \multicolumn{6}{|c|}{ Juglans regia } & \multirow{3}{*}{ N. C } & \multirow{3}{*}{ P.C } \\
\hline & & \multicolumn{2}{|c|}{ Methanol } & \multicolumn{2}{|c|}{ Ethanol } & \multicolumn{2}{|c|}{ Water } & & \\
\hline & & $\begin{array}{l}\text { Zone } \\
\mathrm{mm}\end{array}$ & $\begin{array}{c}\mathrm{MIC} \\
\mathrm{mg} / \mathrm{mL}\end{array}$ & $\begin{array}{l}\text { Zone } \\
\mathrm{mm}\end{array}$ & $\begin{array}{c}\mathrm{MIC} \\
\mathrm{mg} / \mathrm{mL}\end{array}$ & $\begin{array}{l}\text { Zone } \\
\mathrm{mm}\end{array}$ & $\begin{array}{c}\mathrm{MIC} \\
\mathrm{mg} / \mathrm{mL}\end{array}$ & & \\
\hline M. morganii & Clinical & $17.4 \pm 0.45$ & $3.4 \pm 0.75$ & $15.6 \pm 0.65$ & $3.2 \pm 0.44$ & $10.6 \pm 0.54$ & $1.7 \pm 0.76$ & N.D & $16.8 \pm 0.27$ \\
\hline P. aeruginosa & Clinical & $13.2 \pm 0.21$ & $6.5 \pm 0.32$ & $11.3 \pm 0.14$ & $0.7 \pm 0.87$ & $6.5 \pm 0.76$ & $2.3 \pm 0.58$ & N.D & $12.0 \pm 0.21$ \\
\hline A. baumannii & Clinical & $11.3 \pm 0.35$ & $1.3 \pm 0.45$ & $14.3 \pm 0.45$ & $6.3 \pm 0.34$ & $5.3 \pm 0.87$ & $0.7 \pm 0.86$ & N.D & $15.8 \pm 0.13$ \\
\hline H. influenza & Clinical & $9.5 \pm 0.55$ & $5.4 \pm 0.35$ & $8.6 \pm 0.17$ & $1.6 \pm 0.56$ & $4.8 \pm 0.49$ & $3.7 \pm 0.68$ & N.D & $17.5 \pm 0.17$ \\
\hline k. pneumoniae & Clinical & $15.6 \pm 0.15$ & $8.2 \pm 0.15$ & $14.3 \pm 0.55$ & $5.4 \pm 0.65$ & $10.9 \pm 0.77$ & $4.3 \pm 0.31$ & N.D & $20.7 \pm 1.00$ \\
\hline S. aureus & Clinical & $7.3 \pm 0.14$ & $2.5 \pm 0.11$ & $9.1 \pm 0.76$ & $0.8 \pm 0.66$ & $9.8 \pm 0.64$ & $3.2 \pm 0.65$ & N.D & $15.2 \pm 0.11$ \\
\hline \multicolumn{10}{|l|}{ Stem } \\
\hline M. morganii & Clinical & $16.3 \pm 0.75$ & $5.6 \pm 0.18$ & $17.5 \pm 0.36$ & $2.7 \pm 0.57$ & $13.2 \pm 0.71$ & $1.4 \pm 0.45$ & N.D & $19.2 \pm 0.21$ \\
\hline P. aeruginosa & Clinical & $14.6 \pm 0.53$ & $6.3 \pm 0.36$ & $15.3 \pm 0.32$ & $9.2 \pm 0.81$ & $12.3 \pm 0.31$ & $5.3 \pm 0.41$ & N.D & $16.3 \pm 0.20$ \\
\hline A. baumannii & Clinical & $10.7 \pm 0.33$ & $7.2 \pm 0.71$ & $13.2 \pm 0.12$ & $8.5 \pm 0.83$ & $14.6 \pm 0.73$ & $0.9 \pm 0.45$ & N.D & $17.5 \pm 0.26$ \\
\hline H. influenza & Clinical & $10.2 \pm 0.76$ & $1.4 \pm 0.51$ & $16.5 \pm 0.69$ & $0.3 \pm 0.83$ & $8.4 \pm 0.73$ & $0.7 \pm 0.55$ & N.D & $14.3 \pm 0.21$ \\
\hline k. pneumoniae & Clinical & $16.6 \pm 0.47$ & $2.4 \pm 0.15$ & $18.3 \pm 0.43$ & $5.2 \pm 0.84$ & $11.2 \pm 0.21$ & $6.2 \pm 0.74$ & N.D & $19.3 \pm 0.21$ \\
\hline $\begin{array}{l}\text { S. aureus } \\
\text { Bark }\end{array}$ & Clinical & $11.8 \pm 0.43$ & $6.4 \pm 0.17$ & $8.2 \pm 0.53$ & $3.6 \pm 0.13$ & $7.3 \pm 0.65$ & $2.5 \pm 0.56$ & N.D & $11.7 \pm 0.17$ \\
\hline M. morganii & Clinical & $18.5 \pm 0.57$ & $8.3 \pm 0.55$ & $19.4 \pm 0.51$ & $5.2 \pm 0.25$ & $8.3 \pm 0.87$ & $5.8 \pm 0.38$ & N.D & $16.8 \pm 0.27$ \\
\hline P. aeruginosa & Clinical & $15.3 \pm 0.51$ & $5.4 \pm 0.71$ & $17.3 \pm 0.61$ & $2.4 \pm 0.57$ & $11.3 \pm 0.59$ & $4.7 \pm 0.59$ & N.D & $11.0 \pm 0.21$ \\
\hline A. baumannii & Clinical & $16.5 \pm 0.48$ & $4.6 \pm 0.75$ & $15.7 \pm 0.53$ & $6.5 \pm 0.85$ & $15.8 \pm 0.49$ & $6.4 \pm 0.91$ & N.D & $15.8 \pm 0.13$ \\
\hline H. influenza & Clinical & $21.8 \pm 0.76$ & $0.5 \pm 0.19$ & $19.4 \pm 0.38$ & $1.4 \pm 0.96$ & $18.9 \pm 0.81$ & $7.2 \pm 0.61$ & N.D & $17.5 \pm 0.17$ \\
\hline k. pneumoniae & Clinical & $14.6 \pm 0.37$ & $7.7 \pm 0.81$ & $15.8 \pm 0.57$ & $6.8 \pm 0.69$ & $10.3 \pm 0.57$ & $1.4 \pm 0.28$ & N.D & $20.7 \pm 1.00$ \\
\hline S. aureus & Clinical & $18.9 \pm 0.41$ & $8.3 \pm 0.57$ & $19.6 \pm 0.71$ & $7.4 \pm 0.79$ & $15.2 \pm 0.58$ & $3.3 \pm 0.87$ & N.D & $9.5 \pm 0.40$ \\
\hline
\end{tabular}

Table 2. Antibacterial activity of Tamarix aphylla L. extracts against bacterial pathogens

\begin{tabular}{|c|c|c|c|c|c|c|c|c|c|}
\hline \multirow[t]{2}{*}{$\begin{array}{l}\text { Leaf } \\
\text { Microorganisms }\end{array}$} & \multirow{2}{*}{ Origin } & \multicolumn{4}{|c|}{ Tamarix aphylla $L}$. & \multicolumn{2}{|c|}{ Water } & \multirow[b]{2}{*}{ N. C } & \multirow[b]{2}{*}{ P.C } \\
\hline & & $\begin{array}{c}\text { Zone } \\
\mathrm{mm}\end{array}$ & $\begin{array}{c}\mathrm{MIC} \\
\mathrm{mg} / \mathrm{mL}\end{array}$ & $\begin{array}{c}\text { Zone } \\
\mathrm{mm}\end{array}$ & $\begin{array}{c}\mathrm{MIC} \\
\mathrm{mg} / \mathrm{mL}\end{array}$ & $\begin{array}{l}\text { Zone } \\
\mathrm{mm}\end{array}$ & $\begin{array}{c}\mathrm{MIC} \\
\mathrm{mg} / \mathrm{mL}\end{array}$ & & \\
\hline M. morganii & Clinical & $15.2 \pm 0.43$ & $7.3 \pm 0.57$ & $12.6 \pm 0.54$ & $5.7 \pm 0.87$ & $9.2 \pm 0.58$ & $4.5 \pm 0.85$ & N.D & $15.2 \pm 0.11$ \\
\hline P. aeruginosa & Clinical & $14.2 \pm 0.48$ & $5.4 \pm 0.68$ & $11.4 \pm 0.84$ & $6.3 \pm 0.67$ & $6.7 \pm 0.81$ & $3.8 \pm 0.65$ & N.D & $19.2 \pm 0.21$ \\
\hline A. baumannii & Clinical & $11.1 \pm 0.89$ & $3.7 \pm 0.69$ & $9.3 \pm 0.59$ & $4.7 \pm 0.46$ & $8.5 \pm 0.47$ & $5.9 \pm 0.29$ & N.D & $16.3 \pm 0.20$ \\
\hline H. influenza & Clinical & $12.3 \pm 0.41$ & $5.2 \pm 0.81$ & $10.1 \pm 0.28$ & $2.3 \pm 0.58$ & $6.1 \pm 0.44$ & $0.6 \pm 0.71$ & N.D & $17.5 \pm 0.26$ \\
\hline k. pneumoniae & Clinical & $9.6 \pm 0.53$ & $3.4 \pm 0.45$ & $9.8 \pm 0.57$ & $1.4 \pm 0.76$ & $5.2 \pm 0.55$ & $2.7 \pm 0.57$ & N.D & $14.3 \pm 0.21$ \\
\hline \multicolumn{10}{|l|}{ Stem } \\
\hline M. morganii & Clinical & $16.5 \pm 0.11$ & $1.3 \pm 0.41$ & $15.3 \pm 0.58$ & $0.3 \pm 0.85$ & $14.2 \pm 0.48$ & $3.1 \pm 0.14$ & N.D & $16.8 \pm 0.27$ \\
\hline P. aeruginosa & Clinical & $12.4 \pm 0.67$ & $0.4 \pm 0.15$ & $13.1 \pm 0.25$ & $3.4 \pm 0.26$ & $9.2 \pm 0.57$ & $1.4 \pm 1.00$ & N.D & $17.0 \pm 0.21$ \\
\hline A. baumannii & Clinical & $14.6 \pm 0.87$ & $7.3 \pm 0.88$ & $11.3 \pm 0.87$ & $5.2 \pm 0.86$ & $6.2 \pm 0.41$ & $7.6 \pm 0.27$ & N.D & $15.8 \pm 0.13$ \\
\hline H. influenza & Clinical & $11.8 \pm 0.97$ & $6.1 \pm 0.57$ & $14.1 \pm 0.28$ & $7.3 \pm 0.41$ & $10.3 \pm 0.46$ & $5.4 \pm 0.58$ & N.D & $17.5 \pm 0.17$ \\
\hline k. pneumoniae & Clinical & $13.8 \pm 0.88$ & $7.3 \pm 0.78$ & $15.8 \pm 0.58$ & $4.1 \pm 0.43$ & $12.7 \pm 0.71$ & $2.3 \pm 0.86$ & N.D & $20.7 \pm 1.00$ \\
\hline S. aureus & Clinical & $10.1 \pm 0.29$ & $0.4 \pm 0.65$ & $9.5 \pm 0.78$ & $7.3 \pm 0.41$ & $5.3 \pm 0.57$ & $8.1 \pm 0.57$ & N.D & $15.2 \pm 0.11$ \\
\hline \multicolumn{10}{|c|}{ 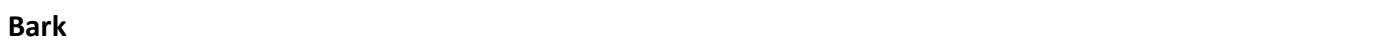 } \\
\hline M. morganii & Clinical & $18.3 \pm 0.41$ & $2.8 \pm 0.43$ & $17.6 \pm 0.44$ & $1.2 \pm 0.27$ & $12.2 \pm 0.55$ & $4.2 \pm 0.42$ & N.D & $19.2 \pm 0.21$ \\
\hline P. aeruginosa & Clinical & $16.2 \pm 0.48$ & $1.2 \pm 0.57$ & $14.3 \pm 0.24$ & $3.3 \pm 0.47$ & $11.4 \pm 0.64$ & $3.4 \pm 0.58$ & N.D & $16.3 \pm 0.20$ \\
\hline A. baumannii & Clinical & $17.1 \pm 0.89$ & $7.8 \pm 0.24$ & $21.5 \pm 0.78$ & $1.4 \pm 0.24$ & $14.8 \pm 0.81$ & $5.6 \pm 0.15$ & N.D & $17.5 \pm 0.26$ \\
\hline H. influenza & Clinical & $19.3 \pm 0.41$ & $8.4 \pm 0.23$ & $15.4 \pm 0.25$ & $3.9 \pm 0.26$ & $12.4 \pm 0.45$ & $0.8 \pm 0.96$ & N.D & $14.3 \pm 0.21$ \\
\hline k. pneumoniae & Clinical & $17.6 \pm 0.55$ & $5.1 \pm 0.87$ & $14.8 \pm 0.88$ & $4.3 \pm 0.22$ & $11.3 \pm 0.65$ & $3.7 \pm 0.41$ & N.D & $19.3 \pm 0.21$ \\
\hline S. aureus & Clinical & $15.3 \pm 0.57$ & $3.8 \pm 0.36$ & $16.4 \pm 0.55$ & $2.8 \pm 0.44$ & $14.4 \pm 0.24$ & $4.8 \pm 0.41$ & N.D & $16.8 \pm 0.27$ \\
\hline
\end{tabular}


Khalid et al. | J Pure Appl Microbiol | 14(2):1133-1142 | June 2020 | https://doi.org/10.22207/JPAM.14.2.08

Table 3. Antibacterial activity of Acacia modesta (Wall.) extracts against bacterial pathogens

\begin{tabular}{|c|c|c|c|c|c|c|c|c|c|}
\hline \multirow{3}{*}{$\begin{array}{l}\text { Leaf } \\
\text { Microorganisms }\end{array}$} & \multirow{3}{*}{ Origin } & \multicolumn{6}{|c|}{ Acacia modesta (Wall.) } & \multirow[b]{3}{*}{ N. C } & \multirow[b]{3}{*}{ P.C } \\
\hline & & \multicolumn{2}{|c|}{ Methanol } & \multicolumn{2}{|c|}{ Ethanol } & \multicolumn{2}{|c|}{ Water } & & \\
\hline & & $\begin{array}{l}\text { Zone } \\
\mathrm{mm}\end{array}$ & $\begin{array}{c}\mathrm{MIC} \\
\mathrm{mg} / \mathrm{mL}\end{array}$ & $\begin{array}{l}\text { Zone } \\
\mathrm{mm}\end{array}$ & $\begin{array}{c}\mathrm{MIC} \\
\mathrm{mg} / \mathrm{mL}\end{array}$ & $\begin{array}{l}\text { Zone } \\
\mathrm{mm}\end{array}$ & $\begin{array}{c}\mathrm{MIC} \\
\mathrm{mg} / \mathrm{mL}\end{array}$ & & \\
\hline M. morganii & Clinical & $8.2 \pm 0.14$ & $2.7 \pm 0.51$ & $11.4 \pm 0.74$ & $2.3 \pm 0.43$ & $6.4 \pm 0.48$ & $2.3 \pm C$ & N.D & $17.0 \pm 0.21$ \\
\hline P. aeruginosa & Clinical & $9.8 \pm 0.58$ & $4.3 \pm 0.61$ & $9.3 \pm 0.54$ & $5.2 \pm 0.28$ & $5.8 \pm 0.91$ & $4.3 \pm 0.14$ & N.D & $15.8 \pm 0.13$ \\
\hline A. baumannii & Clinical & $11.5 \pm 0.47$ & $1.8 \pm 0.21$ & $8.2 \pm 0.28$ & $0.4 \pm 0.62$ & $7.3 \pm 0.41$ & $0.8 \pm 0.32$ & N.D & $17.5 \pm 0.17$ \\
\hline H. influenza & Clinical & $15.5 \pm 0.58$ & $7.4 \pm 0.57$ & $12.6 \pm 0.41$ & $6.1 \pm 0.12$ & $8.1 \pm 0.22$ & $2.2 \pm 0.54$ & N.D & $20.7 \pm 1.00$ \\
\hline k. pneumoniae & Clinical & $10.1 \pm 0.47$ & $5.8 \pm 0.41$ & $13.3 \pm 0.74$ & $3.7 \pm 0.58$ & $10.3 \pm 0.32$ & $5.3 \pm 0.47$ & N.D & $15.2 \pm 0.11$ \\
\hline S. aureus & Clinical & $8.5 \pm 0.87$ & $3.1 \pm 0.32$ & $9.8 \pm 0.45$ & $1.4 \pm 0.66$ & $5.1 \pm 0.27$ & $1.4 \pm 0.45$ & N.D & $19.2 \pm 0.21$ \\
\hline \multicolumn{10}{|c|}{ (6) } \\
\hline M. morganii & Clinical & $17.4 \pm 0.45$ & $9.5 \pm 0.15$ & $16.8 \pm 0.43$ & $8.1 \pm 0.54$ & $12.4 \pm 0.45$ & $2.3 \pm 0.43$ & N.D & $16.3 \pm 0.20$ \\
\hline P. aeruginosa & Clinical & $19.8 \pm 0.91$ & $8.4 \pm 0.26$ & $19.3 \pm 0.91$ & $7.3 \pm 0.41$ & $14.5 \pm 0.57$ & $5.3 \pm 0.51$ & N.D & $17.5 \pm 0.26$ \\
\hline A. baumannii & Clinical & $17.3 \pm 0.22$ & $7.2 \pm 0.29$ & $20.4 \pm 0.22$ & $5.8 \pm 0.52$ & $18.2 \pm 0.44$ & $4.3 \pm 0.14$ & N.D & $14.3 \pm 0.21$ \\
\hline H. influenza & Clinical & $16.3 \pm 0.41$ & $5.2 \pm 0.41$ & $14.2 \pm 0.26$ & $3.7 \pm 0.61$ & $9.3 \pm 0.71$ & $0.5 \pm 0.61$ & N.D & $19.3 \pm 0.21$ \\
\hline k. pneumoniae & Clinical & $13.4 \pm 0.95$ & $4.2 \pm 0.88$ & $17.4 \pm 0.56$ & $8.2 \pm 0.74$ & $11.6 \pm 0.57$ & $6.4 \pm 0.45$ & N.D & $16.8 \pm 0.27$ \\
\hline S. aureus & Clinical & $20.1 \pm 0.47$ & $8.5 \pm 0.31$ & $15.6 \pm 0.65$ & $6.7 \pm 0.85$ & $13.6 \pm 0.41$ & $1.8 \pm 0.58$ & N.D & $17.0 \pm 0.21$ \\
\hline \multicolumn{10}{|c|}{ 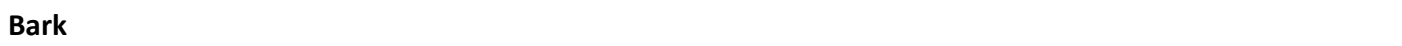 } \\
\hline M. morganii & Clinical & $11.1 \pm 0.44$ & $5.3 \pm 0.41$ & $14.3 \pm 0.57$ & $7.3 \pm 0.25$ & $9.3 \pm 0.44$ & $3.4 \pm 0.41$ & N.D & $15.2 \pm 0.11$ \\
\hline P. aeruginosa & Clinical & $9.2 \pm 0.25$ & $1.4 \pm 0.43$ & $10.5 \pm 0.47$ & $5.2 \pm 0.12$ & $7.8 \pm 0.58$ & $3.5 \pm 0.25$ & N.D & $19.2 \pm 0.21$ \\
\hline A. baumannii & Clinical & $7.3 \pm 0.87$ & $3.7 \pm 0.58$ & $7.2 \pm 0.66$ & $1.3 \pm 0.84$ & $4.6 \pm 0.47$ & $2.5 \pm 0.55$ & N.D & $16.3 \pm 0.20$ \\
\hline H. influenza & Clinical & $3.2 \pm 0.25$ & $0.1 \pm 0.81$ & $2.4 \pm 0.85$ & $0.4 \pm 0.21$ & $6.3 \pm 0.24$ & $4.3 \pm 0.67$ & N.D & $17.5 \pm 0.26$ \\
\hline k. pneumoniae & Clinical & $2.8 \pm 0.47$ & $1.9 \pm 0.91$ & $5.4 \pm 0.77$ & $2.8 \pm 0.57$ & $3.4 \pm 0.92$ & $1.3 \pm 0.47$ & N.D & $14.3 \pm 0.21$ \\
\hline S. aureus & Clinical & $9.3 \pm 0.87$ & $14.4 \pm 0.47$ & $8.3 \pm 0.41$ & $5.1 \pm 0.32$ & $6.3 \pm 0.41$ & $1.9 \pm 0.81$ & N.D & $19.3 \pm 0.21$ \\
\hline
\end{tabular}

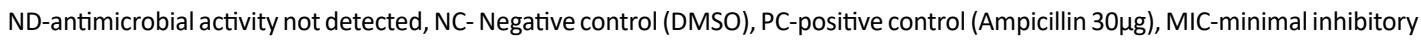
concentration, M. morganii - Marginella morganii, P. aeruginosa Pseudomonas aeruginosa, A. baumannii - Acinetobacter baumannii, H. influenza - Haemophilus influenza, K. pneumonia - Klebsiella pneumoniae, S. aureus - Staphylococcus aureus.

were dispensed into each well and plates were incubated at $37^{\circ} \mathrm{C}$ aerobically for $18 \mathrm{~h}$. At the end of each incubation period, the zone of bacterial inhibition of the extract material was measured ${ }^{13}$. The minimum inhibitory concentrations (MICs) were recorded by agar dilution and micro-broth dilution assays ${ }^{14}$, using around $5000 \mu \mathrm{g} / \mathrm{mL}$ as an extract concentration. Plant extracts showing promising antimicrobial activity were also tested to check the formation of biofilm through in vitro assays.

\section{In vitro assays}

The biofilm forming ability of pathogenic strains were assessed quantitatively as well as qualitatively using microtitre plate assay and by tube assay ${ }^{5}$, respectively.

\section{Microtiter plate assay}

The bacterial strains were transferred to LB broth from nutrient agar plates and incubated for $72 \mathrm{~h}$ at $37^{\circ} \mathrm{C}$ under static conditions. Each sterile well of the flat-bottom microtiter plate was filled with 200 uL overnight culture. LB broth without culture served as a control for each strain. After designated time, the plates were emptied by tapping and washed three times with phosphatebuffered saline (PBS; $\mathrm{pH} \mathrm{7.3)} \mathrm{to} \mathrm{remove} \mathrm{free}$ floating cells. The plates were then stained with $0.1 \%$ crystal violet solution (CVS) and kept for drying after washing with $95 \%$ ethanol to remove excess color. Micro-Plate reader (Perkin Elmer, Victor X3 2030 multi-label reader) was used to record the optical density $\left(O D_{595}\right)$ of wells. The average values of the control wells were subtracted from the mean value of each strain. The standard deviation was calculated with average values after repeating experiments in triplicate, and the OD values $\geq 0.01$ were reflected in the attachment index to the walls and biofilm formation.

\section{Tube assay}

Qualitative evaluation of biofilm formation was carried out through tube assay with some modifications. A loopful of each strain 
was inoculated in tubes containing two $\mathrm{mL}$ of appropriately sterilized LB broth and incubated at $37^{\circ} \mathrm{C}$ for $72 \mathrm{~h}$. The tubes were decanted, washed with PBS (PH 7.3) and air-dried. CVS [0.1\%, w/v] was used to stain the dried tubes to visually observe the adherent layer on the wall and bottom of the tubes.

\section{Cytotoxicity analysis}

Hemolytic activity of plant extracts was conducted by following the method used by ${ }^{15}$. Briefly, freshly collected human blood ( $3 \mathrm{~mL}$ ) was gently mixed in heparinized tubes (to avoid coagulation) and transferred into a sterile Falcon tube $(15 \mathrm{~mL})$ followed by centrifugation for 5

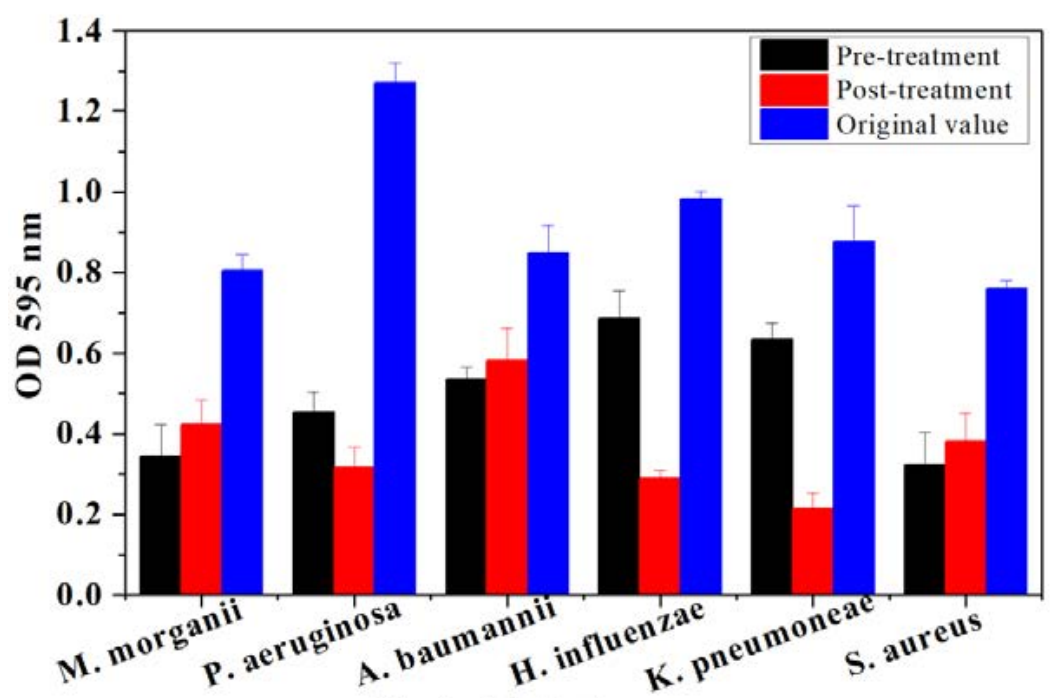

Bacterial strains

Fig. 1. Comparative analysis of biofilm growth of six bacterial strains on a microtiter plate before and after pre and post treatment by Juglans regia bark. At the end of 72-h controlled incubation, the biofilm formation was quantified via staining with crystal violet. Following staining, the spectrophotometric absorbances were recorded at $\mathrm{OD}_{595}$. Bars represent means \pm standard errors for three replicates.

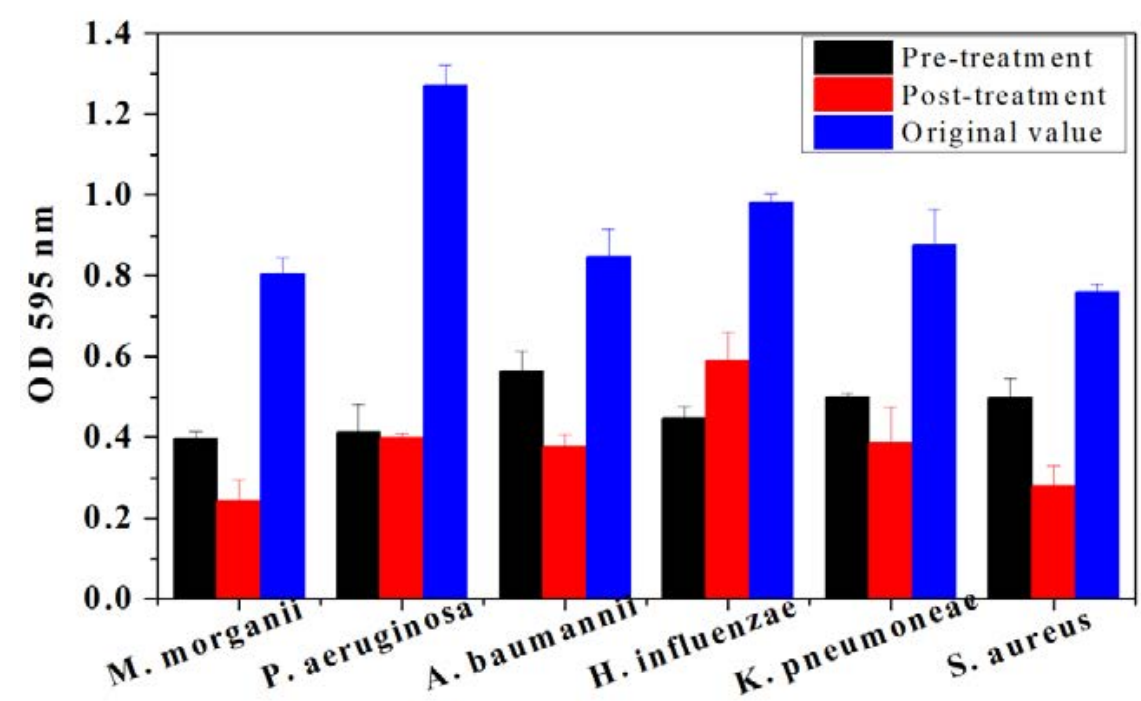

Bacterial strains

Fig. 2. Comparative analysis of biofilm growth of six bacterial strains on a microtiter plate before and after pre and post treatment by Tamarix aphylla bark. Bars represent means \pm standard errors for three replicates. 
$\min$ at $850 \mathrm{~g}$. The supernatant was decanted, and RBCs were washed thrice with chilled sterile PBS solution. Various extracts of the plant $(20$ $\mu \mathrm{L}$ ) were taken in $2 \mathrm{~mL}$ Eppendorf tubes; diluted ten times with RBCs suspension $\left(7.068 \times 10^{8}\right.$ cell/ $\mathrm{mL}$ ) and incubated at $37^{\circ} \mathrm{C}$ for $30 \mathrm{~min}$. After brief centrifugation, collected supernatants $(100 \mu \mathrm{L})$ were diluted with chilled PBS $(900 \mu \mathrm{L})$ and added to 96 well plates. Triton X-100 (0.1\%) and PBS were taken as positive and negative controls, respectively, for each assay.

\section{RESULTS}

Antibacterial activity of selected medicinal plants

The antibacterial activities of extracts of different parts (leaves, stems, and barks) of three medicinal plants such as Juglans regia, Tamarix aphylla L. and Acacia modesta (Wall.) were investigated against six bacterial pathogens by well diffusion method, and the results are summarized in Tables 1, 2 and 3. The results revealed that plants extracts exhibited different degrees of antibacterial activities against all tested microbes. Table 1 demonstrates the results of antibacterial activity of J. regia extracts. Maximum inhibitory effect of $J$. regia extract was recorded against $H$. influenza strain with MIC $0.5 \pm 0.19 \mathrm{mg} / \mathrm{mL}$ and inhibition zone of $21.8 \pm 0.76 \mathrm{~mm}$. In contrast with bark tissue, the leaf and stem showed relatively less antibacterial activities against all tested strains. In the case of T. aphylla $L$. plant, the maximum zone of inhibition, i.e., $21.5 \pm 0.78$ $\mathrm{mm}$ was recorded against $A$. baumannii and least activity was measured to be $14.3 \pm 0.24$ against $P$. aeruginosa (Table 2 ). Noticeably, among the plant extracts tested, ethanolic extract of bark of T. aphylla $L$. displayed the superior antibacterial potential when compared with other parts. The A. modesta stem extract displayed the zone inhibition, i.e., $20.1 \pm 0.47 \mathrm{~mm}$ against $S$. aureus strain and the lowest value of $13.4 \pm 0.95 \mathrm{~mm}$ against $k$. pneumoniae was recorded.

Biofilm formation and anti-biofilm activity of selected medicinal plants

In order to determine the extent to which selected bacterial isolates formed biofilms, the strains were subjected to Microtiter plate, and tube assay and biofilm growth were monitored after $72 \mathrm{~h}$. Comparative analysis of biofilm formation revealed that $P$. aeruginosa strain exhibited the highest optical density $\left(O D_{595}=1.2713\right)$, whereas the least biofilm/planktonic $O_{595}$ value $(O D=0.7598)$ was recorded in case of $S$. aureus. The observation of biofilm growth through tube assay further confirmed the biofilm formation capability of the tested strains.

The plant tissues presenting maximum antimicrobial activity were used for both pre

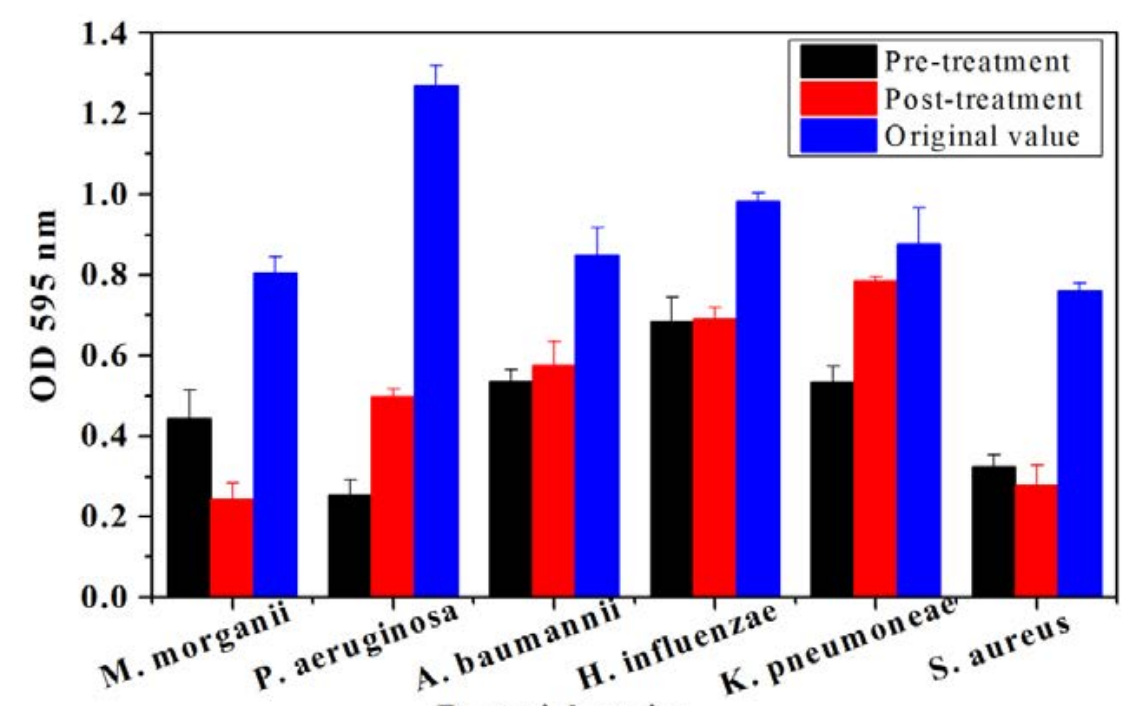

Bacterial strains

Fig. 3. Comparative analysis of biofilm growth of six bacterial strains on a microtiter plate before and after pre and post treatment by Acacia modesta stem. Bars represent means \pm standard errors for three replicates. 
and post treatment in-vitro assays. From Fig. 1 , it is evident, that root bark extract of J. regia significantly decreased the biofilm forming activity for all pathogenic strains compared to the original OD recorded for the six strains. The maximum OD reductions were found in the case of $P$. aeruginosa. The OD percentage reductions recorded were 64.35 and $75.2 \%$ after pre- and post-treatment assays, respectively. Similarly, pre and posttreatment $P$. aeruginosa with the bark extract of $T$. aphylla led to 67.51 and $68.64 \%$ reduction in absorbance as compared to OD without any treatment (Fig. 2). The treatments with stem extract of $A$. modesta also considerably inhibited the biofilm capability of $P$. aeruginosa (Fig. 3).

\section{Cytotoxicity study}

The cytotoxic potential of plant extracts was analyzed by carrying out the hemolytic activity against human erythrocytes. The results are shown in Fig. 4 as percentage lysis of erythrocytes by comparing the absorbance of samples with the positive control (Triton X-100). The positive control displayed almost $100 \%$ erythrocytes lysis; whereas the negative control [phosphate buffer saline (PBS)] showed no RBCs lysis. The results indicated that hemolytic activities of tested plants extracts were found to be non-significant. In comparison to positive control, J. regia bark, T. aphylla bark, and $A$. modesta stem extract showed $2.52 \pm 1.03$, $3.48 \pm 1.08$ and $4.79 \pm 1.09$ hemolytic activity, respectively.

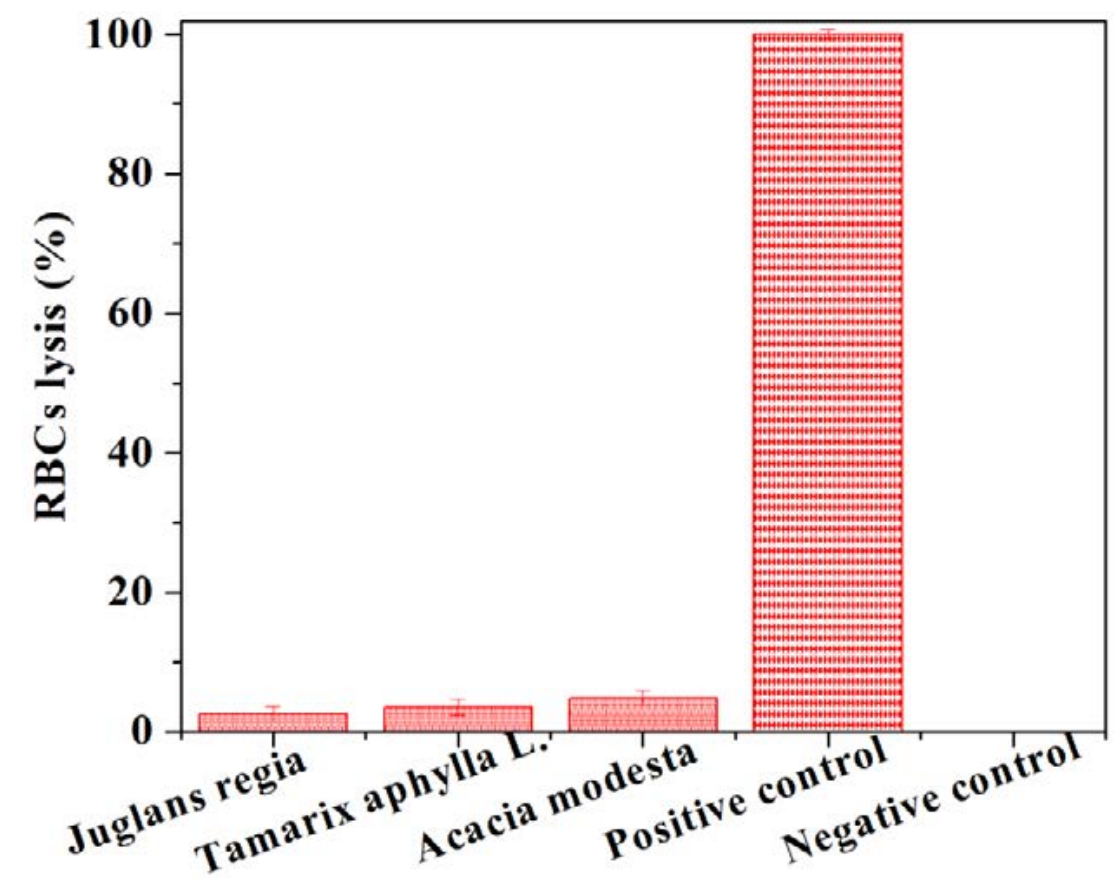

Fig. 4. Cytotoxicity assay by heamolytic activity of various plant extracts. Each bar is determinant of mean of three readings.

\section{DISCUSSION}

Herein, three ethnobotanical plants including J. regia, T. aphyla and $A$. modesta were assessed for antibacterial activity against bacterial pathogens. All the tested plants tested presented the significant antibacterial efficiencies against bacterial isolates. The high antimicrobial potential of J. regia aqueous and methanolic extracts was recorded against MRSA strains with zones of inhibition more than $20 \mathrm{~mm}$ and MICs values of 0.31 and $0.53 \mathrm{mg} / \mathrm{mL}$, respectively. J. regia (walnut tree) is a temperate forest tree commonly found in Asia. The dried bark of this tree is conventionally used in Pakistan for improving oral hygiene and promoting teeth brightening. Earlier studies reported the antimicrobial activity of this plant against bacteria and fungi that may be due to the presence of polyphenols s,2,9-15. $^{1,}$ 
Noticeably, among the plant extracts tested, the bark of J. regia and T. aphylla showed the higher antimicrobial potential that might be due the accumulation of flavonoids content in the bark as resported earleir ${ }^{16,17}$. Like that, the bark of J. regia and T. aphylla has been particularly demontrated previously to have a higher antimicrobial potential as compared to other parts ${ }^{18,19}$. Furthermore, Stem extract of $A$. modesta also showed the superior antibacterial potential when compared with other parts. Comparable potential of stem extract of A. modesta has also been extensively reported previously ${ }^{20-23}$.

The ethanolic extract of $T$. aphyla showed remarkable activity against sixteen Gram-positive and Gram -negative bacterial strains. As compared to the standard drug, the highly significant activity of Acacia modesta and other medicinal plants extracts was recorded by Napar et al. ${ }^{15}$ against $S$. aureus, $B$. subtilis and $E$. coli. The stem extracts of $A$. modesta with five bacterial strains showed that this specific part of the plant has profound antibacterial activity, and same results were noted by ${ }^{17}$. The methanolic extract of $A$. modesta displayed maximum zone of inhibition of $8 \mathrm{~mm}$ against $E$. faecalis, $S$. aureus, and $S$. typhi, and did not show any activity against $B$. subtalis and $P$. aeruginosa $a^{18}$.

It has been demonstrated that overall antimicrobial efficacy primarily accredited to the occurrence of secondary metabolites such as alkaloids, tannins, steroids, flavonoids and terpenoids in plant extracts ${ }^{19,20}$. Although, the precise mode of action of plant extracts is not yet fully explored; it is known that the efficacy of the extract mainly depends on the type of solvent used. Moreover, Gram-negative bacteria are more susceptible to antimicrobials as compared to grampositive bacteria presumably due to non-diffusible lipopolysaccharide membrane surrounding the cell wall in gram-negative bacteria ${ }^{21}$. Additionally, the periplasmatic space contains enzymes which are capable of engulfing foreign molecules incorporated from the outside ${ }^{21}$. Results of biofilm growth pointed out the fact that $P$. aeruginosa displayed the highest ability to form biofilm among the strains tested. The comparable result has also been demonstrated earlier by several investigators $^{22-24}$. P. aeruginosa, an opportunistic human pathogen, is a commonly studied biofilm forming model organism ${ }^{25-27}$. Nevertheless, less than $4.0 \%$ cases, the oral cavity are occupied by Pseudomonas ${ }^{28}$, and patients with cystic fibrosis are most often a host of this strain ${ }^{29}$. Tightly regulated biofilm development by pathogenic strain $S$. aureus has also demonstrated by prior reports ${ }^{30}$. Moreover, a higher anti-biofilm potential for the root bark extract of J. regia, bark extract of T. aphylla and stem extract of $A$. modesta plants was recorded against six pathogenic strains. The same anti-biofilm activity of these plants has been recorded for the number of biofilm forming strains $^{22,24-27}$. Similarly the anti-biofilm effect of several other medicinal plant has also been extensively reported ${ }^{28-31}$.

The cytotoxicity test (hemolytic test) was employed to evaluate the cytotoxic effect of plants extracts. The percent hemolysis remained in the range of 2.52-4.79 that was lower than the previously reported values of percent hemolysis of human erythrocytes by various other plant extracts $^{31-33}$. Radiation-induced hemolysis of human erythrocytes by Psoralea corylifolia extract was studied ${ }^{34}$, and significant protection was recorded against radiation in the concentration range of $25-50 \mu \mathrm{g} / \mathrm{mL}$. Priya et al. ${ }^{35}$ reported that Achyranthes aspera display very low hemolytic activity $(1.3 \%)$ to human erythrocytes. Less hemolytic potential of tested plant extracts as shown in Fig. 2 makes it safe for their exploitation in pharmacological uses. Overall, all extracts investigated possess only small hemolytic activity which favors the use of these plants in safe measures.

\section{CONCLUSIONS}

Given the facts mentioned above, we can suggest that the medicinal plants (commonly available in Pakistan) are a natural source of biologically active constituents of high value that could be used as potential raw material in pharmaceutical industries for the effective control of infectious diseases. In conclusion, the tested plants-based extract exhibited appropriate antimicrobial and anti-biofilm activities against the tested microorganisms. The cytotoxicity of various plants extract assessed through hemolytic test revealed that the tested plants show only negligible cytotoxicity compared to the positive control. Therefore, the results of the present 
study highlight the therapeutic prospect of plants under study as general therapy amongst numerous ethnic groups and conventional therapeutic and remedial experts for the treatment of various infectious diseases.

\section{ACKNOWLEDGMENTS}

All listed author(s) are thankful to their representative universities/institutes for providing the related support to compile this work.

\section{CONFLICT OF INTEREST}

The authors declare that there is no conflict of interest.

\section{FUNDING}

None.

\section{AUTHORS' CONTRIBUTION}

All listed author(s) have made a substantial, direct and intellectual contribution to the work, and approved it for publication.

\section{ETHICS STATEMENT}

This article does not contain any studies with human participants or animals performed by any of the authors.

\section{DATA AVAILABILITY}

Not applicable.

\section{REFERENCES}

1. Bilal $M$, Zhao $Y$, Iqbal HM. Development and characterization of essential oils incorporated chitosan-based cues with antibacterial and antifungal potentialities. Journal of Radiation Research and Applied Sciences. 2020;13(1):174-9. https://doi.org/ 10.1080/16878507.2020.1719336

2. Bilal $M$, Rasheed $T$, Iqbal HM, Hu H, Wang W, Zhang $X$. Macromolecular agents with antimicrobial potentialities: A drive to combat antimicrobial resistance. Int J Biol Macromol. 2017;103:554-74. https://doi.org/10.1016/j.ijbiomac.2017.05.071

3. Tepe B, Daferera D, Sokmen M, Polissiou M, Sokmen A. In vitro antimicrobial and antioxidant activities of the essential oils and various extracts of Thymus eigii M. Zohary et PH Davis. J Agric Food Chem. 2004;52(5):1132-7. https://doi.org/10.1021/jf035094l

4. Edeoga HO, Okwu DE, Mbaebie BO. Phytochemical constituents of some Nigerian medicinal plants. African Journal of Biotechnology. 2005;4(7):685-8. https://doi.org/10.5897/AJB2005.000-3127

5. Jain K, Parida S, Mangwani N, Dash HR, Das S. Isolation and characterization of biofilm-forming bacteria and associated extracellular polymeric substances from oral cavity. Annals of Microbiology. 2013;63(4):155362. https://doi.org/10.1007/s13213-013-0618-9

6. Braxton EE, Ehrlich GD, Hall-Stoodley L, et al. Role of biofilms in neurosurgical device-related infections. Neurosurg Rev. 2005;28(4):249-55. https://doi. org/10.1007/s10143-005-0403-8

7. Majeed FA, Munir H, Rashid R, Zubair MT. Antimicrobial, cytotoxicity, mutagenicity and anti-epileptic potential of ethanol extracts of a multipurpose medicinal plant Dalbergia sissoo. Biocatal Agric Biotechnol. 2019;19:101155. https://doi.org/10.1016/j. bcab.2019. 101155

8. Yang L, Liu Y, Wu H, Hoiby N, Molin S, Song ZJ. Current understanding of multi-species biofilms. IJOS. 2011;3(2):74-81.

9. Ahmad F, Taj MB, Ramzan M, et al. Flacourtia indica based biogenic nanoparticles: development, characterization, and bioactivity against wound associated pathogens. Materials Research Express. 2020;7(1):015026. https://doi. org/10.1088/2053-1591/ab6123

10. Rasheed T, Bilal M, Iqbal HM, Li C. Green biosynthesis of silver nanoparticles using leaves extract of Artemisia vulgaris and their potential biomedical applications. Colloids and Surfaces B: Biointerfaces. 2017;158:40815. https://doi.org/10.1016/j.colsurfb.2017.07.020

11. Oza G, Reyes-Calderon A, Mewada A, et al. Plantbased metal and metal alloy nanoparticle synthesis: a comprehensive mechanistic approach. Journal of Materials Science. 2020;1-22.

12. Khalid M, Bilal M, Hassani D, Iqbal HM, Huang D. Antimicrobial, antioxidant, cytotoxicity and LC-MS analyses of Aerva javanica: an ethnomedicinally important plant. J Biol Regul Homeost Agents. 2017;31(4):963-9.

13. Oliveira I, Sousa A, Ferreira IC, Bento A, Estevinho L, Pereira JA. Total phenols, antioxidant potential and antimicrobial activity of walnut (Juglans regia L.) green husks. Food Chem Toxicol. 2008;46(7):2326-31. https:// doi.org/10.1016/j.fct.2008.03.017

14. Noumi E, Snoussi M, Hajlaoui H, Valentin E, Bakhrouf A. Antifungal properties of Salvadora persica and Juglans regia L. extracts against oral Candida strains. Eur J Clin Microbiol Infect Dis. 2010;29(1):81. https:// doi.org/10.1007/s10096-009-0824-3

15. Napar AA, Bux $\mathrm{H}$, Zia MA, et al. Antimicrobial and antioxidant activities of Mimosaceae plants; Acacia modesta Wall (Phulai), Prosopis cineraria (Linn.) and Prosopis juliflora (Swartz). J Med Plant Res. 2012;6(15):2962-70. https://doi.org/10.5897/JMPR11. 1349

16. Sen A, Batra A. Evaluation of antimicrobial activity of different solvent extracts of medicinal plant: Melia azedarach L. Int J Curr Pharm Res. 2012;4(2):67-73.

17. Asghar R, Ahmad M, Zafar M, Akram A, Mahmood J, Hassan M. Antibacterial Efficacy of Acacia modesta Wall (Miswak) against Dental Pathogen. Pak J Biol Sci. 2003;6(24):2024-5. https://doi.org/10.3923/ pjbs.2003.2024.2025

18. Khalid A, Rehman U, Sethi A, et al. Antimicrobial activity analysis of extracts of Acacia modesta, Artimisia 
absinthium, Nigella sativa and Saussurea lappa against Gram positive and Gram negative microorganisms. African Journal of Biotechnology. 2011;10(22):457480.

19. Alma MH, Nitz S, Kollmannsberger $\mathrm{H}$, Digrak $\mathrm{M}$, Efe FT, Yilmaz N. Chemical composition and antimicrobial activity of the essential oils from the gum of Turkish pistachio (Pistacia vera L.). J Agric Food Chem. 2004;52(12):3911-4. https://doi.org/10.1021/ jf040014e

20. Sartorelli P, Marquioreto AD, Amaral-Baroli A, Lima ME, Moreno PR. Chemical composition and antimicrobial activity of the essential oils from two species of Eucalyptus. Phytotherapy Research. 2007;21(3):231-3. https://doi.org/10.1002/ptr.2051

21. Vaara M. Agents that increase the permeability of the outer membrane. Microbiol Mol Biol Rev. 1992;56(3):395-411. https://doi.org/10.1128/ MMBR.56.3.395-411.1992

22. Murphy TF, Kirkham C. Biofilm formation by nontypeable Haemophilus influenzae: strain variability, outer membrane antigen expression and role of pili. BMC Microbiology. 2002;2(1):7. https://doi. org/10.1186/1471-2180-2-7

23. Galli J, Calo L, Ardito F, et al. Biofilm formation by Haemophilus influenzae isolated from adenotonsil tissue samples, and its role in recurrent adenotonsillitis. Acta Otorhinolaryngologica Italica. 2007;27(3):134.

24. Sekhar S, Kumar R, Chakraborti A. Role of biofilm formation in the persistent colonization of Haemophilus influenzae in children from northern India. Indian J Med Microbiol. 2009;58(11):1428-32. https://doi. org/10.1099/jmm.0.010355-0

25. Klausen $\mathrm{M}$, Heydorn $\mathrm{A}$, Ragas $\mathrm{P}$, et al. Biofilm formation by Pseudomonas aeruginosa wild type, flagella and type IV pili mutants. Molecular Microbiology. 2003;48(6):1511-24. https://doi.org/10.1046/j.13652958.2003.03525.x

26. Ghafoor A, Hay ID, Rehm BH. Role of exopolysaccharides in Pseudomonas aeruginosa biofilm formation and architecture. Appl Environ Microbiol.
2011;77(15):5238-46. https://doi.org/10.1128/ AEM.00637-11

27. HeX, Hu W, He J, Guo L, Lux R, Shi W. Community-based interference against integration of Pseudomonas aeruginosa into human salivary microbial biofilm. Mol Oral Microbiol. 2011;26(6):337-52. https://doi. org/10.1111/j.2041-1014.2011.00622.x

28. Botzenhart K, Puhr OF, Doring G. Pseudomonas aeruginosa in the oral cavity: occurrence and age distribution of adult germ carriers. Zentralblatt fur Bakteriologie, Mikrobiologie und Hygiene. 1. Abt. Originale B, Hygiene. 1985;180(5-6):471-9.

29. Komiyama K, Tynan JJ, Habbick BF, Duncan DE, Liepert DJ. Pseudomonas aeruginosa in the oral cavity and sputum of patients with cystic fibrosis. Oral Surgery, Oral Medicine, Oral Pathology. 1985;59(6):590-4. https://doi.org/10.1016/0030-4220(85)90187-2

30. Singhal D, Foreman A, Bardy JJ, Wormald PJ. Staphylococcus aureus biofilms: Nemesis of endoscopic sinus surgery. The Laryngoscope. 2011;121(7):157883. https://doi.org/10.1002/lary.21805

31. Powell WA, Catranis CM, Maynard CA. Design of selfprocessing antimicrobial peptides for plant protection. Lett Appl Microbiol. 2000;31(2):163-8. https://doi. org/10.1046/j.1365-2672.2000.00782.x

32. Sharma P, Sharma JD. In vitro hemolysis of human erythrocytes-by plant extracts with antiplasmodial activity. JJ Ethnopharmacol. 2001;74(3):239-43. https://doi.org/10.1016/S0378-8741(00)00370-6

33. Riaz M, Rasool N, Bukhari IH, et al. In vitro antimicrobial, antioxidant, cytotoxicity and GC-MS analysis of Mazus goodenifolius. Molecules. 2012;17(12):14275-87. https://doi.org/10.3390/molecules171214275

34. Arora R, Dhaker AS, Sharma J, et al. Radical scavenging and radiomodulatory effects of Psoralea corylifolia Linn. substantiated by in vitro assays and EPR spectroscopy. Zeitschrift fur Naturforschung $C$. 2011;66(1-2):35-46. https://doi.org/10.1515/znc2011-1-206

35. Priya CL, Kumar G, Karthik L, Rao KV. Antioxidant activity of Achyranthes aspera Linn stem extracts. Pharmacologyonline. 2010;2(2):228-37. 